\title{
Regulatory Response to the Rise of Fintech Credit in The Netherlands
}

\author{
Fred Huibers
}

Citation: Huibers, Fred. 2021.

Regulatory Response to the Rise of Fintech Credit in The Netherlands. Journal of Risk and Financial Management 14: 368. https:// doi.org/10.3390/jrfm14080368

Academic Editor: Stefano Zedda

Received: 27 June 2021

Accepted: 9 August 2021

Published: 11 August 2021

Publisher's Note: MDPI stays neutral with regard to jurisdictional claims in published maps and institutional affiliations.

Copyright: (c) 2021 by the author Licensee MDPI, Basel, Switzerland. This article is an open access article distributed under the terms and conditions of the Creative Commons Attribution (CC BY) license (https:// creativecommons.org/licenses/by/ $4.0 /)$.
Faculty of Business and Economics, Amsterdam University of Applied Sciences, 1102 CV Amsterdam, The Netherlands; f.e.huibers@hva.nl

\begin{abstract}
The rise of financial technology (fintech) driven business models in banking poses a challenge for financial regulators. While the positive effects on the banking sector in terms of greater diversity and competition are generally recognized and encouraged by regulators, the nature of fintech business models may increase the risk of financial instability. Regulators are exploring ways to resolve this dilemma. The paper in hand makes a contribution to the literature by providing a framework for resolving the dilemma that is evaluated in the context of the regulatory response to the rise of fintech credit in the Netherlands. The semi-structured interviews which we conducted with four senior Dutch regulators resulted in three areas that-from their perspective-required urgent action: fintech credit companies need to lower the risk of overlending, increase pricing transparency, and improve lending standards. These findings were confirmed by the results of they survey among fintech credit clients. The current regulatory response to the rise of fintech in banking in the Netherlands provides an interesting case study that delineates the features of the future regulation of fintech in banking.
\end{abstract}

Keywords: banks' business models; fintech; regulation; risk management; financial stability

\section{Introduction}

The Financial Stability Board (FSB 2017a) defines fintech as: "technologically enabled financial innovation that could result in new business models, applications, processes, or products with an associated material effect on financial markets and institutions, and the provision of financial services" which has been adopted by the Basel Committee on Banking Supervision (BCBS 2018, p. 8) since: "this broad definition is considered useful by the BCBS in light of the current fluidity of fintech developments".

In the past, technologically enabled financial innovation such as the introduction of Automated Teller Machines, electronic payment systems and online banking have significantly changed the manner in which banking services are provided. Increasingly, the physical infrastructure of the branch network has been replaced by a digital network where bankers and their clients communicate mostly by way of computer screens instead of face-to-face. The widespread adoption of these innovations did not, however, result in non-bank market entrants gaining significant market share in the banking industry (Dermine 2017).

This changed with the rise of fintech entrants in the banking market using the most recently developed technology to provide financial services: big data analytics and machine learning. For example, non-bank entrants have almost tripled their market share in the US mortgage lending in the period 2007-2015 (Vives 2017), where 30\% of the dramatic growth is explained by the use of financial technology (Buchak et al. 2018). This resulted in fintech companies increasing their market share in the US mortgage lending market from 5 to $15 \%$ (Bofondi and Gobbi 2017). On the key competitive advantage that the fintech entrants are successfully exploiting at the expense of the incumbents, Vives (2017, p. 98) notes: "With the generation of new business models based on the use of big data, fintech has the potential to disrupt established financial intermediaries and banks in particular 
(...) The fintech firms better screen potential borrowers using improved statistical models based on big data and are more capable to price mortgage risk and price discriminate. They can do so by combining existing data or by using other dimensions of data that traditional banks cannot access".

The focus of this paper is on fintech credit which is defined as "all credit activity facilitated by electronic (online) platforms that are not operated by commercial banks" (Claessens et al. 2018, p. 29). An essential difference between banks and fintech credit companies is that the latter do not take on the credit risk and the commensurate reward but rather act as agents for creditors by servicing the loan for a fee. According to Thakor (2020, p. 4): "platform's compensation comes in the form of loan origination fees $(1 \%-6 \%)$ and late payment fees paid by borrowers in addition to a percentage of all borrower repayments (typically 1\%) that goes as a service fee to the platform." Fintech credit is disintermediated in the sense that: "there is no bank between investors and borrowers that commits its own capital to provide qualitative asset transformation" (Thakor 2020, p. 4).

Increasingly, institutional investors provide most of the funding of the platforms. (Bollaert et al. 2021). Lu (2018) reports that $80 \%$ of the funding of US platform comes from institutional investors.

Fintech entrants have built up a material market presence in the banking market in different countries, mostly in the unsecured consumer loan and small and medium size enterprises (SME) markets (Dermine 2017). According to Cornelli et al. (2020), the global volume of fintech credit has reached \$ 795 billion where most loans were originated in China, the US and the UK. On a per capita basis, the United States, the United Kingdom, the Netherlands, Latvia and Estonia and were the top-five ranked countries (Ziegler et al. 2021). The analysis of the composition of fintech credit activity by borrower segment across countries indicates that the top three countries where fintech credit is predominantly extended to Small and Medium Enterprises (SMEs) rather than consumers are Japan, the Netherlands and Singapore (Claessens et al. 2018). Conversely, the top three markets in terms of predominance of extending fintech credit to consumers are the United States, Germany and New Zealand (Claessens et al. 2018). This focus on this paper is on fintech credit provision for SMEs.

The market entry of fintech credit companies can on the one hand generate positive effects of better value propositions as the result of business model disruption, but can also have important negative effects such as market instability and market integrity issues. This poses a dilemma for regulators. The imposition of existing, traditional regulation can seriously hinder the development of the market entrants, but failure to regulate the entrants can lead to market incidents that are considered socially unacceptable. A key concern for regulators is how this dilemma can be best resolved. The concern has generated scholarly interest and debate (e.g., Vives 2017; Minto et al. 2017; Clements 2019; Omarova 2020; Valverde and Fernández 2020; Allen 2020; Ofir and Sadeh 2020; Bollaert et al. 2021). At one side of the debate are those (e.g., Darolles 2016) that argue that fintech credit providers are "just another form of financial intermediary with a technological bent" (Bollaert et al. 2021, p. 10) and that the regulatory system does not need to be adjusted to accommodate their development. Others (e.g., Philippon 2016) argue that fintech credit providers are likely to generate significant and historically unique benefits that will only materialize if their development is actively accommodated by the regulator. The paper in hand makes a contribution to the literature by providing a framework for resolving the dilemma that is evaluated in the context of the regulatory response to the rise of fintech credit in the Netherlands.

The paper is organized as follows. The following section identifies and evaluates the factors underlying the growth and rising market share of fintech credit. Section 3 offers an analysis of the benefits and risks that result from the growth of the fintech credit and how it poses a dilemma for regulators. We conclude by providing a framework for resolving the dilemma in the context of the findings concerning the regulatory response to the rise of fintech credit in the Netherlands. 


\section{Factors Underlying the Rising Market Share of Fintech Credit}

A number of supply factors have contributed to the rising market share of fintech credit (FSB 2017b). Technological advances in mobile applications in combination with the ubiquitous smart phones have made online lending more convenient, faster and more accessible (Anagnostopoulos 2018; Alt et al. 2018; Ofir and Sadeh 2020). The rising use of big data analytics and machine learning have made automated credit analysis potentially more accurate and scalable (Stulz 2019). The increasing availability of cloud computing offering flexible and cost effective server capacity is lowering the operating cost of online platforms. In addition, fintech lenders have a structural cost advantage over banks as the market entrants do not have the cost of maintaining a legacy IT and physical infrastructure that has proven to be less and less productive (FSB 2017a; Lu 2018; Anagnostopoulos 2018; Stulz 2019). Fintech lenders also usually have significantly lower cost of regulatory compliance than banks, mainly because-unlike banks-they generally do not accept demand deposits (Claessens et al. 2018). The more stringent regulatory regime that followed the Global Financial Crisis has led to a decreased risk appetite for small and medium sized lending at banks, leaving room for expansion for the fintech lenders (Fenwick et al. 2017; FSB 2017a; Ofir and Sadeh 2020).

On the demand side, the following factors have aided the relative rise of fintech lending (FSB 2017b). The higher customer expectations in terms of user-friendliness, speed, cost and convenience have, as a result of online transaction experience, made them more receptive to switching to online lending platforms. Especially the so-called millennialswhose role in economic life is growing-are accustomed to conducting transactions online (Anagnostopoulos 2018; FSB 2017a). Moreover, the reduced trust in banks as a result of the Global Financial Crisis has stimulated demand for alternative credit providers (Anagnostopoulos 2018; Alt et al. 2018; Stulz 2019; Ofir and Sadeh 2020). Finally, the increasing lower interest rate that banks were offering savers also led to an rise in the willingness to re-allocate savings to the online platforms, as these offer higher returns.

\section{Regulatory Dilemma}

The dynamic growth of fintech credit is challenging regulators to strike the right balance between accommodating financial innovation one the one hand and traditional regulatory objectives of financial stability and market integrity on the other (Ferrarini 2017; Zetzsche et al. 2017; Arner et al. 2017; Anagnostopoulos 2018; Xu and Xu 2019; World Bank 2020). The detailed analysis of the trade-off between the benefits and the risks of financial innovation for achieving these regulatory objectives provides for a solid base for the policy response to resolve the regulatory dilemma (Minto et al. 2017; FSB 2017a; Vives 2017; Omarova 2020).

\subsection{Benefits of Market Entry of Fintech Credit Companies}

Efficiency: the online platform business model of fintech credit can enhance market efficiency by reducing financial intermediation and transaction costs (Arner et al. 2015; Zetzsche et al. 2017; Fenwick et al. 2017; Vives 2017; FSB 2017a; Lu 2018; Thakor 2020; Bollaert et al. 2021). The fintech lending platforms may also lead to better allocation of capital which can contribute to financial stability.

Transparency: fintech credit companies can potentially reduce information asymmetry about underwriting criteria and the pricing of loans by fully automating the process in algorithms which allows for better credit risk pricing and risk management (Ferrarini 2017; FSB 2017a; Magnuson 2018).

Decentralization and diversification: the automation of loan origination, distribution and pricing by fintech lenders have effectively reduced the barriers to entry for market entry. This in turn has led to a more diversified and decentralized lending market that is less vulnerable to the collapse of a single institution of cluster of similar institutions (Fenwick et al. 2017; FSB 2017a; Vives 2017; Minto et al. 2017; Magnuson 2018; Cornelli et al. 2020).

Access: Fintech credit increases access to credit due to the more convenient and client-oriented digitalized business proposition than that of banks (Fenwick et al. 2017; 
FSB 2017a, 2017b; Temelkov and Samonikov 2018; Magnuson 2018; Abbasi et al. 2021a). However, the rise of fintech credit does not only generate benefits but may also have negative implications for financial stability.

\subsection{Risks of Market Entry of Fintech Credit Companies}

Deterioration in lending standards: the agency business model of fintech credit, which relies heavily on origination fees rather than interest margin, may result in over-lending and an erosion of lending standards (FSB 2017a, 2017b; Thakor 2020). This may lead to systemic risk similar to those that materialized as a consequence of the originate-todistribute business model that ended in the Global Financial Crisis, especially if banks response to fintech credit competition is to lower their lending standards.

Procyclicality: fintech credit platforms are more sensitive to fluctuations in economic sentiment than intermediated finance provided by banks (FSB 2017a; Fenwick et al. 2017; FSB 2017b; Ofir and Sadeh 2020). According to FSB (2017a, p. 20): “interaction between investors and borrowers on FinTech lending platforms could potentially exhibit larger swings in sentiment than traditional intermediation of funds as a sudden unexpected rise in non-performing loans could trigger a drying up of new funds. The presence of retail investors could exacerbate this point even further".

Reputational contagion: due to the very limited available risk buffers and-in some cases-non stress-tested risk models of fintech credit providers, a significant and unexpected rise in the volume of non-performing loans could lead to reputation loss that have sector-wide repercussions (Minto et al. 2017; FSB 2017a; Magnuson 2018). According to FSB (2017a, p. 20): "Reputational contagion is a potential concern for FinTech, particularly where activities interact directly with households and businesses. For example, significant and unexpected losses incurred on a single FinTech lending platform could be interpreted as indicating potential losses across the sector. Increased access, combined with risks like cyber risk that suffer from weak link problems, may also increase contagion risk".

\section{Regulatory Response}

The literature on the regulatory response to the rise of fintech is voluminous but onedimensional. Most scholars focus on a specific regulatory action to resolve the dilemma rather than providing a coherent framework that provides criteria to (dynamically) weigh alternative regulatory actions.

The most frequently mentioned regulatory response to the rise of fintech is to set up a regulatory sandbox, which is a regulatory regime that allows market entrants to test and develop their business model without having to comply with the burdensome regulation imposed on incumbents (Ferrarini 2017; He et al. 2017; Bromberg et al. 2017; Zetzsche et al. 2017; Magnuson 2018; De Koker et al. 2019; World Bank 2020; Ringe and Ruof 2020; Ofir and Sadeh 2020). Ringe and Ruof (2020, p. 604), for example, unequivocably recommend a regulatory sandbox: "this paper proposes a regulatory "sandbox"-an experimentation space-as a step towards a regulatory environment where such new business models can thrive. A sandbox would allow market participants to test fintech services in the real market, with real consumers, but under the close scrutiny of the supervisor. The benefit of such an approach is that it fuels the development of new business practices and reduces the "time to market" cycle of financial innovation, while simultaneously safeguarding consumer protection. At the same time, a sandbox allows for mutual learning in a technical field which is sometimes poorly understood, both for firms and for the regulator. This would help to reduce the prevalent regulatory uncertainty for all market participants".

Other scholars point to self-regulation as an appropriate regulatory response in resolving the dilemma (Arner et al. 2015; Ferrarini 2017; Bruckner 2018; Magnuson 2018; Allen 2020; Ofir and Sadeh 2020). An important benefit of self-regulation is that fintech credit companies are generally better equiped to detect risks to financial stability as they are more alert and able to identify and understand the implication of financial innovation than regulators. 
Some scholars argue that the market entry of fintech requires a change in regulatory perspective from entity-based to activity-based (Arner et al. 2015; He et al. 2017; Restoy 2019; Ofir and Sadeh 2020). According to He et al. (2017, p. 15): “More fundamentally, the "unbundling" and migration of services from intermediaries to networks may require regulators to rely less on entity-based regulation and more on activity-based regulation".

Scholars do agree, however, on the need to adjust the current regulatory regime. Examples of the most outspoken scholars on this requirment are Magnuson (2018, p. 1187): "By increasing competition and lowering prices, fintech promises to provide great benefits to society at large. But the changes also call for a broad reassessment of the adequacy of current financial regulation"; and Bruckner (2018, p. 1): "Applying the existing regulatory framework to fintech lenders may do more harm than good".

Regulators are searching for a framework that can be used to formulate a response to resolve the dilemma that they are confronted with as a result of fintech market entry. According to the World Bank (2020, p. 2): "Financial sector policymakers worldwide are finding themselves in a regulatory dilemma when trying to achieve the right balance between enabling innovative Fintech and safeguarding the financial system". The IMF-WBG Global Fintech Survey ${ }^{1}$ revealed that, roughly $73 \%$ of surveyed jurisdictions indicated that they were reviewing and amending their policy framework to enable Fintech investment, innovation, and adoption.

The policy disruption model of Biber et al. (2017) provides a framework for the formulation of the regulatory response in case of disruption by market entry. Biber et al. (2017, p. 1561) define policy disruption as the situation: "When business innovation upends a preexisting business model in a regulated industry, the result can be a disjunction between the structure of the regulatory system governing incumbent firms and the firms disrupting the industry: a policy disruption [...] This Article is the first to offer a comprehensive analytical framework of how business innovation can create policy disruption and how regulators should respond".

However, in formulating the policy disruption model, Biber et al. (2017) take a legal rather than economic perspective as they assume that the normative goal of regulators is organizational neutrality. We have adapted the policy disruption model where the criteria for formulating the policy response are based on the economic trade-off between benefits (return) and costs (risks). This would bring the criteria more in line with the view of the literature (Minto et al. 2017; FSB 2017a; Vives 2017; Omarova 2020). The Financial Stability Board (FSB 2017a, p. 29) states: "The numerous possible benefits and risks need to be evaluated and weighed against one another in order to identify potential implications of FinTech developments for financial stability. In general, the significance of benefits and risks depends on the drivers and inherent market structure in which the activity is conducted, as well as the trade-offs that may be inherent in innovation".

Figure 1 shows the four policy response options of the policy disruption model of Biber et al. (2017). The adapted criteria for choosing among the four options are shown in the rectangular four boxes.

Block: if the fintech market entry yields low (or even negative) economic benefits and/or is detrimental towards the achievement of regulatory objectives of financial stability and market integrity, the regulator should block "the upstart from entering the market, either in light of public interest concerns or because of old-fashioned rent seeking." (Biber et al. 2017, p. 1603). A recent example is the blocking of the introduction of the digital currency Libra by Facebook. ${ }^{2}$ The most vocal opponent is the French Minister of Finance Bruno Le Maire: "Libra also represents a systemic risk from the moment when you have two billion users". 3 


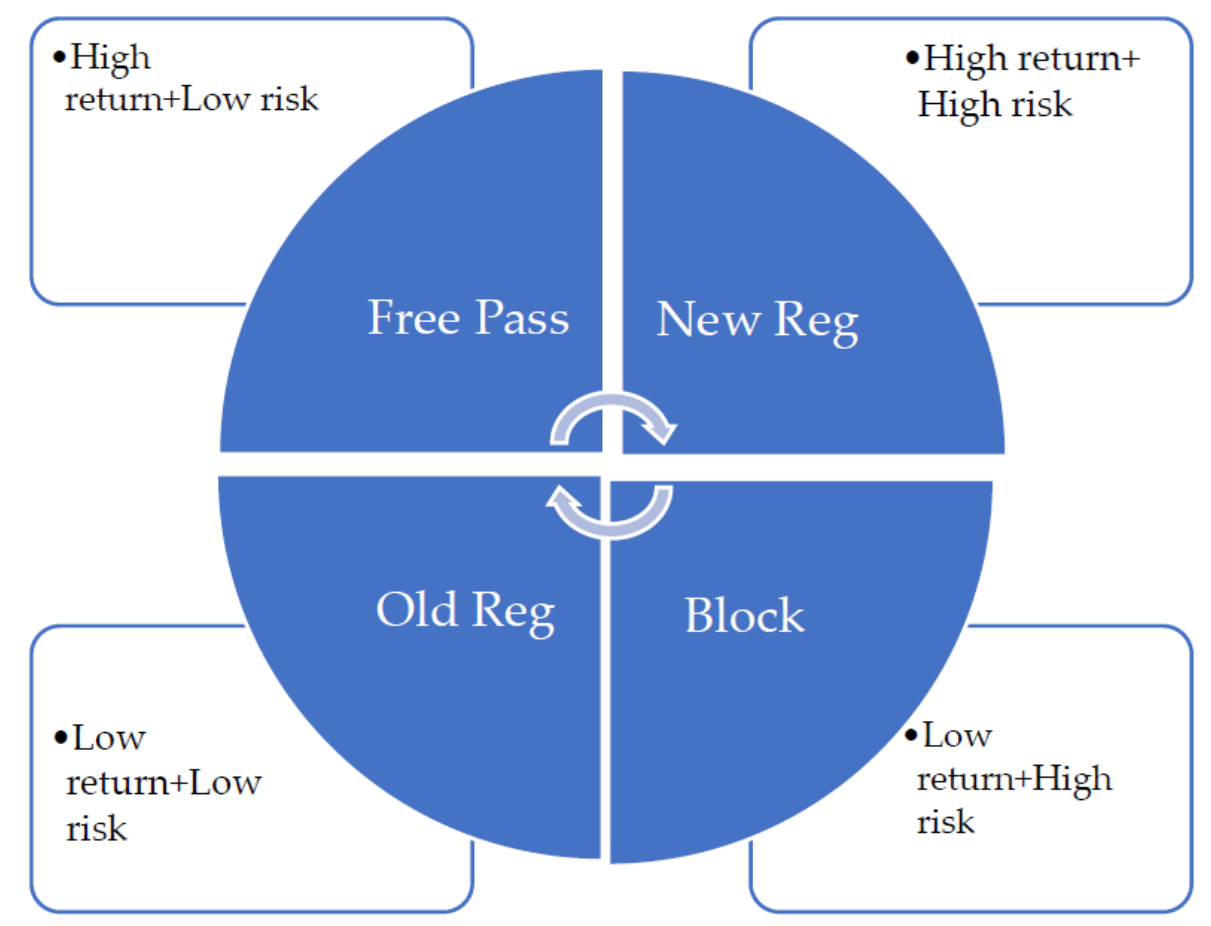

Figure 1. Regulatory response options and criteria. Source: Biber et al. (2017).

Free Pass: conversely, if the market entry brings significant benefits while not significantly adding to existing risks in the financial system, the regulator would refrain from imposing the existing ('old') regulatory burden on the market entrants in order to stimulate innovation, as the risks of market entry are acceptable: "giving the upstart a Free Pass and letting the old business model and regulatory structure decline, with the loss of the associated regulatory benefits from that regulatory structure." An example of this response is to allow the fintech entrants to self-regulate (Arner et al. 2015; Ferrarini 2017; Bruckner 2018; Magnuson 2018; Allen 2020; Ofir and Sadeh 2020).

Old Reg: if market entry by fintech does not bring significant benefits but at the same time does not significantly increase risks in the financial system, the regulator should require both the incumbents and market entrants to comply with existing ('old') regulations. An example is the regulatory response to market entry of digital banks such as Revolut and N26 that are confronted with "unaltered fundamental requirements for banking. New digital banks still must comply with basic regulatory requirements such as Anti-Money Laundering/Counter-Terrorism Financing (AML/CTF), consumer protection rules, risk management and prudential requirements like minimum capital". ${ }^{4}$

New Reg: if regulators recognize the significant benefit that the market entry of fintech generates but are nevertheless concerned with the additional risk to that entry brings to the financial system, they should change the old regime in order to mitigate these risks. An example is the change in regulatory regime that digital banks have to comply with when they move from the regulatory sandbox and need to obtain a banking license to operate in the open market (Ofir and Sadeh 2020).

The regulatory response can migrate among the four options depending on market developments. This is indicated with the arrows in the center of Figure 1.

\section{Regulation of Fintech Credit in The Netherlands}

The Netherlands is-together with the United States, the United Kingdom, Latvia and Estonia-in the global top five in terms of fintech credit volume on a per capita basis (Ziegler et al. 2021). The analysis of the composition of fintech credit activity by borrower segment across countries indicates that the Netherlands-together with Japan and Singapore- 
is among the top three countries where fintech credit is predominantly extended to Small and Medium Enterprises (SMEs) rather than consumers (Claessens et al. 2018).

Compared to the contribution of SMEs towards gross national product, tax revenue and employment, SMEs are substantially underserved in business lending (Lu 2018; Abbasi et al. 2021b). Lu (2018, p. 342) states: “In the United Kingdom, SMEs account for $99.9 \%$ of the total business population, $60 \%$ of private-sector employment, and $50 \%$ of the national GDP (...) only $17 \%$ of business loans in the UK were given to SMEs." The mismatch between the economic contribution of and credit provision to SMEs is even more pronounced in the Netherlands, where the contribution of SMEs to private-sector employment and GDP is, respectively, $71 \%$ and $62 \%$ while SMEs receive only $14 \%$ of business loans. ${ }^{5}$

Dutch banks extended approximately $€ 74$ billion in credit to companies in 2018, of which almost $€ 10$ billion are classified as small business loans with a principal amount of less than $€ 1$ million. The amounts below $€ 1$ million are mainly for SMEs, with amounts above a million mostly for large companies. The total amount of outstanding lending amounted to approximately $€ 300$ billion, of which $€ 130$ billion was to SMEs. ${ }^{6}$

According to the Dutch Central Bureau for Statistics (CBS), in 2020 almost a quarter $(63,900)$ of SMEs in the Netherlands needed external financing. Only $37 \%(23,800$ SMEs $)$ ultimately obtained the loan. ${ }^{7}$ An important reason why SMEs decide not to apply for bank loans is that they expect to be rejected or that the conditions (particularly the level of the interest rates) will not be attractive. CBS notes that SMEs are increasingly relying on non-bank financing among other things, due to the ever-increasing tightening of the acceptance criteria by banks, which mainly affected SMEs, which are increasingly turning to alternatives.

This is confirmed by the Cental Planning Bureau $(\mathrm{CPB})^{8}$ which notes that: "In the Netherlands, banks grant fewer SME loan applications than in the rest of the eurozone. That may be right, but the difference is remarkably large. This is probably not due to the financial health of SMEs, which is comparable to the rest of the eurozone (...) corporate loans in general, and SME loans in particular, can also be squeezed out of the market because other loans are more profitable for the banks (...) Market power of banks: due to high market concentration, there may be little competition in the Netherlands. The relatively high interest rates are an indication of this".

The recognition of the important benefits that market entry of fintech credit in SME lending generates in terms of efficiency, access, diversity and transparency resonates in the statement made by the Dutch Minister of Finance Hoekstra in April 2019: "Innovation in the financial sector (fintech) is of great importance. Innovation, and the entry of new innovative players, contributes to diversity and competition in the financial sector, and thus to a healthy market economy. Innovation is an important domain in my financial sector agenda".

In reaction to these developments, the Dutch Minister of Economics on 11 July 2019 publicly acknowledged the need to address the market failure in the provision of SME loans by actively supporting the growth of fintech alternatives to banks. The fintech credit companies were exempted from compliance with existing regulations and the government provided funding for the newly established meta-organization (Berkowitz and Souchaud 2019) Stichting MKB Financiering (SMF) consisting of a represenative number of Dutch fintech SME credit providers to further the growth and professionalism the sector through self-regulation.

In practice, the Dutch regulatory authorities Autoriteit Financiële Markten (AFM) and the Dutch central bank De Nederlandsche Bank (DNB) gave the fintech credit companies a Free Pass: "The AFM and DNB want to offer tailor-made solutions to ensure that market parties can market their innovative financial products, services or business models without unnecessary obstacles". ${ }^{9}$ However, the AFM and DNB also expressed their concern about the increased risks of market entry by fintech credit to market integrity: "innovative products and services can make the playing fs are increasing" ${ }^{\prime 10}$ and financial stability: 
"DNB is in the first camp and is positive about fintech. We just need to be aware of the potential risks (...) The operational stability of institutions and their service providers is expected to demand more supervisory attention under the influence of technological developments". ${ }^{11}$

The Free Pass regulatory response is therefore conditional; fintech credit companiesthrough self-regulation-are exempted from compliance to existing regulation provided that they take measures to ensure that professionalism is increased to a standards that lower the risks to financial stability and market integrity to levels that are acceptable to DNB and AFM.

The Dutch regulatory response to the fintech credit entry was not unique. Berkowitz and Souchaud (2019) present a detailed analysis of the process of self-regulation in France in which a representative group of fintech credit providers-united in the meta-organization Financement Participatif France-were granted a Free Pass conditional on developing standards to ensure that the growth of the sector would not lead to unacceptably high risks to financial stability and merket integrity. "FPF was set up to answer the need to develop platforms and new technologies, with the aim of building trust with regulators, and protecting the industry from black sheep". (Berkowitz and Souchaud 2019, p. 962). The first step in developing standards is the co-construction of a code of ethics: "a lot of quite weak organizations that wanted to establish their legitimacy and also base their legitimacy on being part of a group, because they had a shared vision but they had to sell it. And one platform alone, just one economic player, cannot sell it (...) In a collective bricolage, that is, a collective tinkering process, FPF members defined principles to guide their practices. These proposals resulted in the co-construction of a code of ethics that sets industry standards for transparency, transaction security, consumer protection, and compliance. All FPF members must abide by this code to remain members of the main national crowdfunding association, in direct contact with the government."(Berkowitz and Souchaud 2019, pp. 968,970). The goal of setting fintech credit standards-minimum requirements for the transparency, security, and integrity of the operations of fintech credit companies-is to obtain and maintain a legitimate market position for fintech credit companies. Legitimacy is reached when the external stakeholders (regulators and SME clients of fintech) trust that the industry does not encompass unacceptable market integrity and financial stability risks.

While the Dutch SMF-similar to the French FPF-did produce a code of ethics ${ }^{12}$, to date it has not operationalized the code into standards. The failure of the fintech companies to effectively self-regulate while taking a progressively more important role role in the market for SME loans (their market share has reached $22 \%{ }^{13}$ ), has raised concerns within the Dutch government to such levels that it has decided to take remedial action.

In September 2020, the Dutch government provided funding for the development of these standards to the research group of the Centre For Financial Innovation of the Amsterdam University of Applied Sciences. The leader of the project (also the author of this paper) enlisted the commitment from the leading fintech credit companies ${ }^{14}$ and from the stakeholders to actively provide the input required to formulate the standards. The semi-structured interviews which were conducted with four senior representatives of AFM (two representatives) and DNB (two representatives) resulted in three areas that-from their perspective-required urgent action from the SMF and their members. First, the calculation and documentation of the pricing of the products of the fintech credit companies needs to be transparent and standardized. According to the regulators, current unclear and complicated communication concerning pricing makes it difficult for SMEs to compare alternatives and make an informed financing decision. The current situation leads to suboptimal provision of loans to SMEs.

Second, the regulators observe a high risk of overlending and an erosion of lending standards that needs to be mitigated by the requirement that fintech credit companies need to improve the documentation to SME clients so that the financing offered optimally matches their financial situation and prospects. Interestingly, the regulators observe that 
reliance of financial advisors to provide such documentation is not acceptable; it is deemed the responsibility of the fintech credit companies.

Third, unsurprisingly given the government position on the limited effectiveness of the current state of self-regulation, the regulators require the SMF to formulate, implement and enforce standards, while also increasing their membership in order to increase the market representativeness of the meta-organization. Only then can self-regulation be relied upon to control the risks to a level that is deemed acceptable by the regulators.

In order to check if the main observations of the regulators are congruent with the view of the clients of the Dutch SME fintech credit platforms, we conducted a survey among the 430 members of the entrepreneurial interest group ONL ${ }^{15}$; the largest such organisation that is deemed representative for the Dutch SMEs. A total of 124 financial decision-makers at Dutch SMEs responded which implies a response rate of 29\% (124/430). We used the standard online survey tool that is made available by the board of the interest group. Respondents were asked to rate their level of agreement (full agreement, partial agreement, or non agreement) with each of eight statement concerning the service that the require from the fintech credit companies. The results of the survey are presented in Table 1.

Table 1. The level of agreement with statements concerning the service that the require from the fintech credit companies.

\begin{tabular}{lccc}
\hline \multicolumn{1}{c}{ Statement I Require: } & Full Agreement & Partial Agreement & Non Agreement \\
\hline full and detailed insight in pricing & $24 \%$ & $59 \%$ & $17 \%$ \\
indication of application process time & $13 \%$ & $67 \%$ & $20 \%$ \\
optimal solution to financial situation & $15 \%$ & $68 \%$ & $17 \%$ \\
\hline bad debt statistics & $15 \%$ & $60 \%$ & $25 \%$ \\
motivation for request for collateral & $28 \%$ & $56 \%$ & $16 \%$ \\
\hline customer complaints statistics & $19 \%$ & $56 \%$ & $25 \%$ \\
insight in risk management & $18 \%$ & $66 \%$ & $16 \%$ \\
complete indication of documentation requirements & $16 \%$ & $66 \%$ & $\mathbf{1 8 \%}$ \\
Average & $\mathbf{1 8 \%}$ & $\mathbf{6 2 \%}$ & $\mathbf{1 8 \%}$ \\
\hline Source: author survey & & & \\
Red numbers indicate highest & & \\
\hline
\end{tabular}

On average, $18 \%$ of the respondents agreed and disagreed with the statement posed to them. The percentage of respondents that agree with the statements "I require full and detailed in sight in the pricing of the fintech credit offer" and "I require that the fintech credit companies offers me a motivation for their request for collateral" of, respectively, $24 \%$ and $28 \%$ is above this average value of $18 \%$. These are marked in red in Table 1. The percentage of the respondents that disagreed with the statements "I require insight in bad debt statistics" and "I require insight in customer complaints statistics" of $25 \%$ is above this average value of $18 \%$. These are marked in red in Table 1. On average, $62 \%$ of the respondents partially agreed with the statement posed to them. The percentage of respondents that partially agree with the statements "I require an indication of how long the processing of my application will take ", "I require that the fintech credit companies offer me the optimal solution to my financial situation", "I require insight in risk management used by the fintech credit company", and "I require a complete indication of documentation that I need to submit with my application" of, respectively, $67 \%, 68 \%, 66 \%$ and $66 \%$, is above this average value of $62 \%$.

The results indicate that-from the perspective of the financial decision makers at SMEs-taking measures to improve pricing transparency and communication that explains demands for collateral are the measures that fintech companies should take to increase the trust of clients. Regulators similarly emphasize that improvements in pricing transparency and the documentation to SME clients, showing that the financing offered optimally matches their financial situation and prospects, is needed to increase their trust in fin- 
tech credit companies. In reaction to the research findings, the group of leading fintech credit companies that committed themselves to the research project are currently in the process of evaluating the implementation of the standards required to obtain a legitimate market position.

To place further emphasis on the importance of the development and implementation of standards by a representative meta-organization, on 9 April 2021 the AFM published a report ${ }^{16}$, in which the authorities explained if and when they would change their regulatory response from conditional Free Pass to New Reg. To date, the regulator was dissatisfied with the scope and substance of self-regulation. In terms of scope, the membership of the SMF was considered too limited compared to the sector and, in terms of substance, the professional standards (and the sanctions for non-compliance) were seen as too lenient. The regulator expressed concerns that self-regulation was not sufficiently addressing the growing risks that the rise of fintech credit was posing to the financial system and that they were considering new regulation.

\section{Conclusions}

The semi-structured interviews which we conducted with four senior Dutch regulators resulted in three areas that-from their perspective-required urgent action: fintech credit companies need to lower the risk of overlending, increase pricing transparency, and improve lending standards. These findings were confirmed by the results of they survey among fintech credit clients. The current regulatory response to the rise of fintech in banking in the Netherlands provides an interesting case study that delineates the features of the future regulation of fintech in banking.

This paper presents a framework for formulating a regulatory response to fintech entry in SME banking (Figure 1). The current regulatory response to the rise of fintech in corporate banking in the Netherlands provides an interesting case study that delineates the features of its future regulation. The changing position of the regulator in the Netherlands shows that the response is not static; we conclude that regulators-not only in the Netherlands but also in other jurisdictions-should continuously weigh the benefits against the risk of the growing role of fintech in the financial system in order to find the response that best resolves the dilemma that they are confronted with. By carefully weighing the benefits against the risks and selecting the commensurate policy response and applying the framework proposed in this paper, all stakeholders are likely to benefit from an efficient, accessible and transparency fintech credit market.

Funding: This research was funded by Nederlandse Organisatie voor Wetenschappelijk Onderzoek, Nationaal Regieorgaan Praktijkgericht Onderzoek SIA (Netherlands Organization for Scientific Research, National Governing Body for Practice-Oriented Research SIA), grant number RAAK.MKB12.007.

Data Availability Statement: Data sharing not applicable.

Conflicts of Interest: The authors declare no conflict of interest.

\section{Notes}

www.imf.org > Publications > PPEA2019024 June 2019 (accessed on 25 June 2021).

https: / / fortune.com/2020/10/12/ facebook-libra-currency-g7-bankers-crypto/ (accessed on 25 June 2021).

https: / /www.bbc.com/news/business-49677146 (accessed on 25 June 2021).

https: / / www.cgap.org/blog/some-countries-have-digital-bank-licenses-others-have-digital-banks (accessed on 25 June 2021).

CBS analyses 2021 (staatvanhetmkb.nl) (accessed on 25 June 2021).

https:/ / economie.rabobank.com/publicaties/2019/juni/alternatieve-financieringsvormen-mkb-blijven-groeien/\#de69d36f-faa8 -4ecd-8115-a367882baa30 (accessed on 25 June 2021).

https:/ / www.cbs.nl/nl-nl/publicatie/2021/06/ financieringsmonitor-2020 (accessed on 25 June 2021).

https:/ / www.cpb.nl/sites/default/files/omnidownload/CPB\%20Policy\%20Brief\%20MKB-bankfinanciering\%20-\%2011\%20juni. pdf (accessed on 25 June 2021). 


\section{References}

Abbasi, Kaleemullah, Ashraful Alam, Noor Ahmed Brohi, Imtiaz Ali Brohi, and Shahzad Nasim. 2021a. P2P lending Fintechs and SMEs' access to finance. Economics Letters 204: 1-3. [CrossRef]

Abbasi, Kaleemullah, Ashraful Alam, Min Anna Du, and Toan Luu Duc Huynh. 2021b. Fintech, sme efficiency and national culture: Evidence from oecd countries. Technological Forecasting \& Social Change 163: 1-9. [CrossRef]

Allen, Hillary J. 2020. Experimental strategies for regulating FinTech. Journal of Law E Innovation 3: 1-30.

Alt, Rainer, Roman Beck, and Martin T. Smits. 2018. Fintech and the transformation of the financial industry. Electronic Markets. The International Journal on Networked Business 28: 235-43. [CrossRef]

Anagnostopoulos, Ioannis. 2018. Fintech and regtech: Impact on regulators and banks. Journal of Economics andBusiness 100: 7-25. [CrossRef]

Arner, Douglas W., Janos Barberis, and Ross P. Buckley. 2015. The evolution of Fintech: A new post-crisis paradigm. Georgetown Journal of International Law 47: 1-45. [CrossRef]

Arner, Douglas W., Dirk A. Zetzsche, Ross P. Buckley, and Jonas N. Barberis. 2017. FinTech and RegTech: Enabling innovation while preserving financial stability. Georgetown Journal of International Affairs 18: 47-58. [CrossRef]

BCBS (Basel Committee on Banking Supervision). 2018. Sound Practices: Implications of Fintech Developments for Banks and Bank Supervisors. Available online: www.bis.org (accessed on 25 June 2021).

Berkowitz, Heloise, and Antoine Souchaud. 2019. (Self-)regulation of sharing economy platforms through partial meta organizing. Journal of Business Ethics 159: 961-76. [CrossRef]

Biber, Eric, Sarah E.Light, J. B. Ruhl, and James Salzman. 2017. Regulating business innovation as policy disruption: From the model T to Airbnb. Vanderbilt Law Review 70: 1561-626.

Bofondi, Marcello, and Giorgio Gobbi. 2017. The big promise of FinTech. European Economy 2: 107-19.

Bollaert, Helen, Florencio Lopez-de-Silanes, and Armin Schwienbacher. 2021. Fintech and access to finance. Journal of Corporate Finance 68: 1-14. [CrossRef]

Bromberg, Lev, Andres Godwin, and Ian Ramsay. 2017. Fintech sandboxes: Achieving a balance between regulationand innovation. Journal of Banking and Finance Law and Practice 28: 314-36.

Bruckner, Matthew A. 2018. Regulating fintech lending. Banking E Financial Services Policy Report 37: 1-7.

Buchak, Greg, Gregor Matvos, Tomasz Piskorski, and Amit Seru A. 2018. Fintech, regulatory arbitrage, and the rise of shadow banks. Journal of Financial Economics 130: 453-83. [CrossRef]

Claessens, Stijn, Jon Frost, Grant Turner, and Feng Zhu. 2018. Fintech credit markets around the world: Size, drivers and policy issues. BIS Quarterly Review, 29-49. Available online: https:/ / ssrn.com/abstract=3288096 (accessed on 25 June 2021).

Clements, Ryan. 2019. Regulating Fintech in Canada and the United States: Comparison, Challenges and Opportunities. School of Public Policy Research Series. Calgary: University of Calgary, pp. 1-40.

Cornelli, Giulio, Jon Frost, Leonardo Gambacorta, Raghavendra Rau, Robert Wardrop, and Tania Ziegler. 2020. Fintech and big tech credit: A new database. BIS Working Papers 887: 1-33.

Darolles, Serge. 2016. The rise of fintechs and their regulation. Financial Stability Review 20: 85-92.

De Koker, Louis, Nicholas Morris, and Sue Jaffer. 2019. Regulating financial services in an era of technological disruption. Law in Context 36: 90-112. [CrossRef]

Dermine, Jean. 2017. Digital Disruption and Bank Lending. European Economy 2: 63-76.

Fenwick, Mark, Joseh A. McCahery, and Erik P.M. Vermeulen. 2017. Fintech and the financing of entrepreneurs: From crowdfunding to marketplace lending. ECGI Working Paper Series in Law 369: 1-45. [CrossRef]

Ferrarini, Guido. 2017. Regulating fintech: Crowdfunding and beyond. European Economy 2: 121-42.

FSB (Financial Stability Board). 2017a. Financial Stability Implications from Fintech: Supervisory and Regulatory Issues that Merit Authorities' Attentions. Available online: http:/ /www.fsb.org/wp-content/uploads/R270617.pdf (accessed on 25 June 2021).

FSB (Financial Stability Board). 2017b. FinTech Credit: Market Structure, Business Models and Financial Stability Implications. Available online: http:/ / www.bis.org/publ/cgfs_fsb1.htm4 (accessed on 25 June 2021). 
He, Dong, Ross Leckow, Vikram Haksar, Tomasso Griffoli, Nigel Jenkinson, Mikari Kashima, Tanai Khiaonarong, Céline Rochon, and Hervé Tourpe. 2017. Fintech and financial services: Initial considerations. International Monetary Fund Staff Discussion Note 1-49.

Lu, Lerong. 2018. Promoting SME finance in the context of the fintech revolution: A case study of the UK's practice and regulation. Banking and Finance Law Review 33: 317-43.

Magnuson, William. 2018. Regulating fintech. Vanderbilt Law Review 71: 1167-226.

Minto, Andrea, Moritz Voelkerling, and Melanie Wulf. 2017. Separating apples from oranges: Identifying threats to financial stability originating from FinTech. Capital Markets Law Journal 12: 428-65. [CrossRef]

Ofir, Moran, and Ido Sadeh. 2020. More of the Same or Real Transformation: Does FinTech Warrant New Regulation? Available online: http: / / dx.doi.org/10.2139/ssrn.3531718 (accessed on 25 June 2021).

Omarova, Saule T. 2020. Technology v technocracy: Fintech as a regulatory challenge. Journal of Financial Regulation 6: 75-124. [CrossRef]

Philippon, Thomas. 2016. The fintech opportunity. National Bureau of Economic Research 22476: 1-24.

Restoy, Fernando. 2019. Regulating fintech: What is going on, and where are the challenges? Paper presented at the ASBA-BID FELABAN XVI Banking Public-Private Sector Regional Policy Dialogue "Challenges and Opportunities in the New Financial Ecosystem", Washington, DC, USA, 17 October.

Ringe, Wolf-Georg, and Christopher Ruof. 2020. Regulating Fintech in the EU: The Case for a Guided Sandbox. European Journal of Risk Regulation 11: 604-29. [CrossRef]

Stulz, René M. 2019. Fintech, bigtech, and the future of banks. Journal of Applied Corporate Finance 31: 86-97. [CrossRef]

Temelkov, Zoran, and Marija Gogova Samonikov. 2018. The need for fintech companies as non-bank financing alternatives for sme in developing economies. International Journal of Information, Business and Management 10: 25-33.

Thakor, Anjan V. 2020. Fintech and banking: What do we know? Journal of Financial Intermediation 41: 1-13. [CrossRef]

Valverde, Santiago Carbó, and Franciso Rodríguez Fernández. 2020. Financial digitalization: Banks, fintech, bigtech, and consumers. Journal of Financial Management, Markets and Institutions 8: 1-13. [CrossRef]

Vives, Xavier. 2017. The impact of FinTech on banking. European Economy 2: 97-105.

World Bank. 2020. How Regulators Respond To FinTech: Evaluating the Different Approaches-Sandboxes and Beyond. Fintech Note 5: $1-53$.

Xu, Zhong, and Ruihui Xu. 2019. Regulating fintech for sustainable development in the People's Republic of China. ADBI Working Paper Series 1023: 1-19.

Zetzsche, Dirk A., Ross P. Buckley, Janos N. Barberis, and Douglas W. Arner. 2017. Regulating a revolution: From regulatory sandboxes to smart regulation. Fordham Journal of Corporate and Financial Law 23: 31-103. [CrossRef]

Ziegler, Tania, Rotem Shneor, Karsten Wenzlaff, Jaesik Kim, Felipe Ferride Paes, Krishnamurthy Suresh, Zheng Bryan, Leyla Mammadova, and Nicola Adams. 2021. Trends, Opportunities and Challenges for Lending, Equity, and Non-Investment Alternative Finance Models. The Global Alternative Finance Market Benchmarking Report 22: 1-241. 